\title{
Outcome of Therapy
}

National Cancer Institute

\section{Source}

National Cancer Institute. Outcome of Therapy. NCI Thesaurus. Code C18919.

The result of therapy for a given disease or condition in a patient or group of patients. 